Disponível em

http://www.anpad.org.br/rac

RAC, Curitiba, v. 14, n. 5, art. 1,

pp. 780-797, Set./Out. 2010

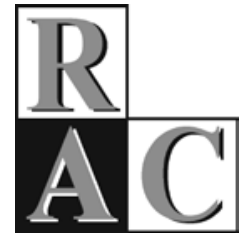

\title{
(Re)contando a Velha História: Reflexões sobre a Gênese do Management
}

The Old Story (Re)told: Reflections about Management Genesis

Fabio Vizeu *

Doutor em Administração de Empresas pela EAESP/FGV.

Professor do PMDA/UP, Curitiba/PR, Brasil.

* Endereço: Fabio Vizeu

Rua Walenty Golas, 371, apto. 401-A, Campo Comprido, Curitiba/PR, 81200-520. E-mail: fabio.vizeu@gmail.com

Copyright (C) 2010 RAC. Todos os direitos, inclusive de tradução, são reservados. É permitido citar parte de artigos sem autorização prévia desde que seja identificada a fonte. 


\title{
RESUMO
}

Este trabalho pretender minimizar os problemas da ausência da perspectiva histórica no pensamento acadêmico sobre a Administração. Assim, apresentamos uma reflexão pouco utilizada no mainstream da área sobre as condições históricas que permitiram a emergência do Management enquanto instituição moderna, bem como os fatores que condicionaram sua disseminação. Construímos nossa discussão, revisitando textos seminais de historiadores marxistas e institucionalistas interessados em compreender as bases do processo de industrialização capitalista e a consequente institucionalização do saber e da prática do Management. Primeiramente, é na constituição histórica do capitalismo industrial que se observam as condições plurais de emergência e os elementos primitivos das práticas modernas de gestão e organização do trabalho. Um segundo passo foram as demandas específicas do grupo de engenheiros industriais norte-americanos e europeus. Tendo sido apresentadas em associações de classe e jornais especializados, tais demandas intensificaram o debate sobre a sistematização de princípios de Management, um processo de articulação de classe que teve em Taylor seu mais bem sucedido proponente. Na conclusão, apresentamos algumas implicações sobre o entendimento do Management centrado na reflexão que aqui se propôs sobre sua construção histórica.

Palavras-chave: management; história; historiografia; capitalismo industrial; taylorismo.

\begin{abstract}
This paper aims to reduce problems involving the lack of historical perspective in academic thought concerning Management. Thus, we discuss in a way that is unusual in the academic mainstream the historical and social conditions that were important in inducing the rise of Management as a modern institution, in addition to the factors that conditioned its dissemination. We built our discussion revisiting some historians' seminal works, specifically those Marxists and Institutionalists who are interested in capitalist industrialization and in its consequent institutionalization of Management knowledge. First of all, it is in the historical constitution of industrial capitalism that we found the fundamental social transformations to improve modern management practices and modern work organization. The second step was the specific work requirements of American and European industrial engineers. They were presented in a specific debating arena, i.e., its professional association and engineering journals. These work demands intensified the debate about a particular agenda for Management principles, a social process of which Taylor as the most famous participant. In conclusion, we present some implications about the historical development of Management.
\end{abstract}

Key words: management; history; historiography; industrial capitalism; taylorism. 


\section{INTRODUÇÃO}

A ausência de perspectiva histórica na reflexão teórica sobre o Management tem gerado graves problemas de entendimento e análise deste objeto, seja para a prática de pesquisa (Üsdiken \& Kieser, 2004), seja para o ensino (Bedeian, 2004). A resposta a esta carência pode ser medida pela recente intensificação do tratamento específico da história dentro dos congressos de Management nos Estados Unidos e na Europa, dois grandes centros de desenvolvimento desta prática. Apesar disso, o senso comum compartilhado pela maioria dos praticantes de Management - e mesmo dentro do meio acadêmico - tem em conta este termo como a representação de um sistema de princípios universais, presentes durante todos os períodos históricos, porém revelados apenas recentemente pelos 'papas' da chamada abordagem clássica. O que este universalismo tem de mais perigoso, enquanto tendência definidora do Management, é negar-lhe seu caráter mais essencial, ou seja, o fato de esta instituição ser uma construção histórica de nosso tempo e, como tal, ser carregada de concepções e pressupostos que somente são devidamente compreendidos, quando situados historicamente (Üsdiken \& Kieser, 2004).

Assim, defendemos a ideia de que, sendo o Management uma construção histórica, seu entendimento por parte dos teóricos e praticantes deste campo deve ser condicionado à investigação sistemática das fontes historiográficas que retratam sua emergência, fontes estas esquecidas tanto pela literatura voltada para o ensino quanto por aquela endereçada à discussão e construção do entendimento teórico deste tema. Na academia brasileira, por exemplo, a lacuna pela falta de perspectiva histórica se torna agudamente problemática, tendo em conta que o potencial da análise histórica do Management provê entendimento sobre nossas próprias peculiaridades culturais e condições particulares para o exercício da gestão moderna (Vizeu, 2010).

Neste sentido, este trabalho visa discutir as condições históricas e sociais que permitiram a emergência do Management enquanto instituição moderna, em particular considerando-se sua configuração dentro da Administração de empresas econômicas ${ }^{(1)}$. Neste sentido, além dos fatores históricos relacionados à gênese e à configuração original deste instituto, enquanto pensamento gerencial e econômico particular, destacamos os fatores que promoveram sua disseminação no seu país de origem e em outras partes do mundo ocidental. A intenção deste esforço é sinalizar os aspectos caracterizadores do Management, considerando que estes somente podem ser devidamente dimensionados, quando observados a partir de sua construção histórica (Bedeian, 2004). Metodologicamente falando, partimos de uma base historiográfica que, em sua maior parte, se encontra ausente (ou, no mínimo, mal utilizada) na literatura acadêmica brasileira.

Buscamos construir nossa discussão a partir da integração de duas orientações historiográficas em particular: i) a historiografia marxista (ou a baseada em pressupostos do marxismo), que compreende o Management como um sistema fruto da reorganização do modo de produção econômica que emergiu com o capitalismo moderno (Braverman, 1974; Gorz, 1980), onde o processo de industrialização econômica teve papel central (Chandler, 1977; Dobb, 1980; Hobsbawm, 2000; Landes, 1994); ii) a história institucional, fundamentada no processo de institucionalização do saber e da prática do Management, processo este que se configurou especialmente pela gradual organização de um conhecimento especializado e de uma classe profissional a ele vinculada (Chandler, 1977; Jenks, 1960; Pollard, 1965).

Tendo em conta a literatura historiográfica específica deste tema, o primeiro esboço daquilo que chamamos hoje de Management se delineia como resultado da organização social provocada pela Revolução Industrial (Braverman, 1974; Pollard, 1965). Ou seja, a análise histórica da industrialização aponta aspectos importantes dos primórdios destas práticas, no momento em que seus princípios fundamentais foram forjados. Assim, iniciamos este artigo tratando dos grandes processos que possibilitaram a formação desta instituição para, em seguida, tratarmos do momento específico em que o Management se sistematiza em uma disciplina organizada e independente. Na conclusão, 
apresentamos algumas implicações sobre o entendimento do Management centrado em sua construção histórica.

\section{CONDIÇÕES HISTÓRICAS PARA A EMERGÊNCIA DO MANAGEMENT: O DESENVOLVIMENTO dO SISTEMA CAPITALISTA DE ProduÇÃo}

De todos os processos e eventos que têm sido lembrados pela historiografia como ponto de partida da era moderna, o advento e a proliferação da produção capitalista figura como aquele de maior consenso dentro das ciências sociais (Dobb, 1980). A partir do desenvolvimento do sistema capitalista é que se constitui a tese de que o Management representa uma forma sofisticada de capitalismo, o capitalismo gerencial (Chandler, 1977). De forma simplificada, esta tese se baseia nos seguintes aspectos: tendo em conta as exigências de autorreprodução do sistema capitalista, nos séculos seguintes ao seu surgimento ocorre o refinamento de seus mecanismos de manutenção por meio de uma revolução na atividade produtiva, que se refere ao controle direto da produção de mercadorias pelos interesses capitalistas, fato este que possibilitou o surgimento de nova lógica manufatureira, de graves consequências econômicas, culturais e políticas, denominada industrialização; por sua vez, esta nova ordem produtiva e econômica se viabilizou com o auxílio de uma nova forma de controle do trabalho, centrada na figura do administrador profissional e especializado. A delimitação deste novo tipo de sistema de administração ocorre em bases e valores eminentemente modernos, dos quais se destacam a racionalidade econômica e a ética do trabalho, sendo esta a base psicológica e moral da administração moderna.

Constituindo uma teoria de amplo escopo, Marx apresenta como ponto de inflexão do período histórico atual o estabelecimento do capitalismo, o sistema econômico com implicações sociais e políticas que irá marcar a transição das sociedades pré-modernas para a era moderna. Para Marx (2002), o capitalismo se caracteriza como um modo de produção específico, dimensionado tanto em um patamar técnico - um sistema de produção voltado para o mercado, onde a mercadoria é a principal construção histórica - quanto em sua dimensão social, em que, a partir da concentração de propriedade em pequenos grupos, nasce uma classe social de não-possuidores, que se obrigam a comercializar a sua força de trabalho que, dentro deste sistema, também representa uma mercadoria.

Nesta perspectiva histórica, o surgimento do capitalismo moderno pode ser demarcado no momento em que os setores produtivos foram subordinados a esta nova ordem econômica, centrada no interesse de remuneração do capital (Dobb, 1980). Esta subordinação se dá especialmente pela perda do controle da produção, sofrida pelo produtor direto. Neste ponto, Marx argumenta que, mesmo sofrendo uma espécie de exploração de seu trabalho, o artesão e o lavrador da Idade Média ainda podiam controlar o seu ofício, tendo em conta que possuíam os meios de produção, detinham todo o saber necessário à produção dos bens e organizavam as condições operacionais necessárias ao processo produtivo. É por isso que Marx viu na apropriação dos ofícios o fundamento da era moderna, já que é a partir deste processo que o capitalismo se torna um mecanismo de exploração do trabalho mais tenaz que aqueles característicos do período histórico precedente.

Logo, é na destruição do ofício com a fragmentação do processo de trabalho que reside o princípio político fundamental do capitalismo (Braverman, 1981; Dobb, 1980; Marx, 2002). É dele que derivam as transformações na estrutura de classes da sociedade feudal, alterando as bases que sustentavam a preponderância da classe dominante e o equilíbrio de poder característico deste período. Ou seja, de acordo Marx, o advento do sistema de produção capitalista representou a transição para um novo sistema de classes, sustentado por uma nova base econômica e política.

Em sua fase inicial, o capitalismo se sustenta na atividade mercantil em expansão, dada especialmente pela ampliação geográfica na aquisição e venda de mercadorias e pela consequente monetarização dos mercados de trocas. Este processo foi denominado por fase mercantilista, que teve por um de seus traços mais emblemáticos as incursões além-mar para o comércio das especiarias na 
Índia (Dobb, 1980; Hobsbawm, 1996). Na fase mercantil do capitalismo, o capital era investido em produtos de um mercado mais barato e vendidos em outro mais caro, com a finalidade de remunerar o capital.

Todavia, o capitalismo mercantil tinha uma relação indireta com a produção. Para ampliar o ganho e satisfazer as expectativas de remuneração do capital, foi necessária a expansão do controle capitalista para o interior do processo produtivo, especialmente no âmbito da produção de bens manufaturados. É neste momento que surge o capitalismo industrial. Marx (2002) traça dois caminhos para a transição do mercantilismo ao capitalismo industrial: o refinamento do domínio do capital mercantil sobre a produção manufaturada (expresso no controle dos burgueses mercantis sobre os artesãos e as guildas), e o emburguesamento da classe manufatureira, inicialmente processado na Inglaterra do século dezessete (Hobsbawm, 2000).

A consolidação do capitalismo enquanto sistema global e hegemônico ocorre na segunda metade do século dezenove, momento em que a ideologia burguesa atinge todos os enclaves da sociedade. Neste momento, o capitalismo industrial se aprimora com o desenvolvimento do sistema financeiro de fluxo de capitais - capitalismo financeiro - e com o desenvolvimento da grande empresa e seu controle sobre as relações de mercado - o capitalismo monopolista (Braverman, 1981). Porém, não se deve entender que a industrialização foi a causa dos sistemas de capitalismo moderno, nem o contrário, mas que estes processos se constituíram de forma recorrente, e que representam elementos essenciais e indissociáveis do sistema institucional que caracteriza as sociedades modernas.

\section{O PROCESSO DE INDUSTRIALIZAÇÃO}

A Revolução Industrial representa o evento que marcou um novo período da história moderna, cuja atividade industrial se torna preponderante em relação à agrária, dando condições absolutas para a expansão da economia capitalista. Em parte, deve-se considerar que as bases da Revolução Industrial foram o aprimoramento tecnológico voltado ao aumento da produtividade manufatureira, obtido por meio de melhores dispositivos fabris, especialmente pela mecanização do trabalho manual; novas fontes de energia inanimada, substituindo a força humana e animal; e na melhoria na extração e confecção de matérias-primas, especialmente com a sofisticação da atividade metalúrgica e dos processos químicos (Landes, 1994).

Entretanto, é preciso ter o cuidado de situar devidamente a relação entre as indústrias e as inovações tecnológicas tão mencionadas nos manuais de História, sob pena de não verificar devidamente quais foram as condições de maior significado para o advento desta revolução das 'formas de produzir'. Landes (1994) e Hobsbawm (2000) consideram que a propensão do povo inglês para o desenvolvimento de inovações tecnológicas durante a Revolução Industrial se deve mais ao interesse prático na atividade produtiva do que à revolução cientifica que ocorrera naquele país durante os séculos dezesseis e dezessete, apesar de ambos se sustentarem no instinto empirista de investigação dos fenômenos naturais.

No século dezoito, a Inglaterra era o único país europeu que detinha uma economia realmente sólida, constituída ao longo dos duzentos anos precedentes de desenvolvimento contínuo. Neste período, a Europa desenvolveu um sistema econômico integrado, apoiado pela dicotomia de países economicamente adiantados e outras regiões de economias dependentes, representadas basicamente pelas colônias e outras áreas de controle comercial das potências marítimas e algumas regiões que se especializavam em produtos demandados pelas regiões adiantadas (Hobsbawm, 2000). Graças ao seu progresso interno, dado pelo desenvolvimento econômico de grupos capitalistas que permitiram significativas sobras de capital, e a sua política externa economicamente orientada, em política agressiva e sustentada militarmente, a Inglaterra erigiu-se como o principal articulador desta “economia mundial dos Estados marítimos europeus” (Hobsbawm, 2000, p. 34). 
Além de ter-se desenvolvido pelas oportunidades geradas, como o abrupto incremento da demanda, principalmente externa, por produtos manufaturados, a classe nascente de empreendedores da indústria se constituiu ideologicamente, a partir da formação de uma consciência de classe, que se fortaleceu na medida em que se tornou mais aguda a insatisfação sobre a orientação das políticas econômicas originárias do período pré-industrial inglês e que persistiam durante o século dezoito. Como toda classe emergente, os primeiros empreendedores industriais enfrentaram resistência de algumas facções da sociedade tradicional, como, por exemplo, os artesãos e agricultores. Além disso, as pressões contra os industriais vinham de outros grupos que, a despeito de se terem consolidado no mesmo período histórico, se sentiram prejudicados com as reivindicações de proteção à indústria nacional inglesa. Este é o caso das empresas capitalistas de comércio marítimo que importavam produtos manufaturados (Bendix, 1974).

Certamente, de todas as inovações que possibilitaram a Revolução Industrial, a fábrica é a mais importante. Porém, seu caráter revolucionário não se resume apenas no fato de esta ter representado um novo local para o trabalho, onde se reúne grande número de trabalhadores sob o mesmo teto, mas pelos princípios que subjazem a este novo sistema produtivo. Importante notar que a fábrica alterou a própria estrutura urbana, tendo em vista que, antes dela, o ambiente de trabalho e o doméstico se confundiam (Gorz, 1980; Hobsbawm, 2000). Além disso, o sistema fabril possibilitou novo quadro funcional mediador das relações de trabalho.

Neste sentido, uma das mais significativas transformações na sociedade, provocadas pela fábrica, foi o advento da disciplina fabril. Nas sociedades agrárias, onde o trabalhador detinha o controle das condições de trabalho e ele próprio determinava o ritmo da produção, a noção de tempo correspondia ao ritmo do trabalhador, que era determinado em grande parte por seus diferentes interesses da vida cotidiana que, obviamente, condicionavam a necessidade pecuniária do produtor, mas também o momento certo para o descanso, para o lazer e para o trabalho. Na verdade, a lógica do mercado - que se insere no sistema da manufatura artesanal na figura do intermediário - já correspondia a um fator de transmutação do ritmo do trabalho, sendo prenúncio daquilo que seria vigente no trabalho fabril (Landes, 1994).

Outra significativa transformação social impetrada pelo trabalho fabril foi a divisão sistemática do processo de manufatura. Neste sentido, é importante considerar que este mecanismo também representa importante fundamento para o desenvolvimento do capitalismo. Como afirma Braverman (1981), a divisão do trabalho industrial não se configura no mesmo sentido que a divisão social do trabalho comum a todas as sociedades ao longo da história; na verdade, o fundamento lógico da divisão do trabalho industrial é o fato de este ocorrer no interior do processo de trabalho, ou seja, com a finalidade de obter eficiência operacional na execução da tarefa. É neste sentido que se pode afirmar que a divisão do trabalho industrial se sustenta a partir da reprodução do capital, já que é orientada para a maximização do ganho econômico (Braverman, 1981).

Esta maximização do lucro ocorre especificamente pela alienação do trabalhador sobre o processo de trabalho, quando a função gerencial tem papel fundamental de articular este sistema de fragmentação do trabalho; se na perspectiva do capitalista promove maior produtividade, na perspectiva do trabalhador reduz a autonomia (Gorz, 1980). Assim sendo, sob a égide da divisão interna de tarefas que é processada no modelo fabril de produção, a própria lógica de dominação social do processo de trabalho se insere em novo patamar.

Logo, a ascensão da atividade de gestão, enquanto categoria profissional privilegiada, em nossa sociedade se explica historicamente pelo poder adquirido nesta função, poder este que é garantido pela alienação do controle do processo de trabalho, que caracteriza a lógica capitalista de produção. Sobre este aspecto, Marx (2002) apresenta a noção de trabalhador coletivo, um conceito que ressalta a dicotomia da divisão interna do processo produtivo como medida de melhoria da produtividade do trabalho, mas que, ao mesmo tempo, representa um mecanismo que promove a alienação do trabalho:

O mecanismo específico do período manufatureiro é o trabalhador coletivo, constituído de muitos trabalhadores parciais. As diferentes operações executadas sucessivamente pelo produtor de uma 
mercadoria e que se entrelaçam no conjunto de seu processo de trabalho apresentam-lhe exigências diversas. Numa, tem ele de desenvolver mais força; noutra, mais destreza; numa terceira, atenção mais concentrada, etc.; e o mesmo indivíduo não possui, no mesmo grau, essas qualidades. Depois de separar, tornar independentes e isolar essas diversas operações, são os trabalhadores separados, classificados e grupados [sic] segundo suas qualidades dominantes. Se suas peculiaridades naturais constituem a base em que se implanta a divisão do trabalho, desenvolve a manufatura, uma vez introduzida, forças de trabalho que, por natureza, só são aptas para funções especiais, limitadas. O trabalhador coletivo passa a possuir, então, todas as qualidades produtivas no mesmo grau elevado de virtuosidade e as despende ao mesmo tempo, da maneira mais econômica, individualizando todos os seus órgãos em trabalhadores especiais ou em grupos de trabalho aplicados exclusivamente em suas funções específicas (Marx, 2002, pp. 403-404).

No conceito de Marx de trabalhador coletivo reside a necessidade de uma nova função no processo de trabalho: a coordenação das diferentes partes isoladas, garantindo o sincronismo entre as tarefas separadas e mantendo o fluxo do trabalho. Neste aspecto é que a gerência emerge como função essencial para a indústria capitalista; esta, além de viabilizar a precisão mecânica do complexo sistema fabril, permite que o capitalista obtenha um ganho extra, baseado na perda histórica do trabalhador de uma importante fonte de poder, a autonomia. É por causa desta perda que surgem novas formas de confronto entre trabalhadores e elite, das quais se destacam os movimentos sindicais e as greves (Gorz, 1980).

Finalmente, o aspecto essencial do modelo de controle que se concretiza no trabalho fabril é a disciplina. Identificando sua origem na área militar, Weber (1974) sinaliza o papel decisivo da disciplina na organização de empreendimentos que envolvem grande número de trabalhadores, como, por exemplo, as grandes plantações coloniais ou os empreendimentos do Egito faraônico. Contudo, é na fábrica moderna que este autor reconhece a superioridade da disciplina enquanto fator de produtividade e controle racional. Isto porque a disciplina fabril é condicionada às prerrogativas da racionalidade econômica, como sugere o seguinte trecho:

Com a ajuda de métodos de mensuração adequados, a lucratividade ótima do trabalhador individual é calculada como a de qualquer meio material de produção. À base desse cálculo, o sistema americano de 'administração científica' obteve os maiores triunfos no condicionamento e treinamento racional do comportamento de trabalho. As consequências finais são obtidas com a mecanização e disciplina da fábrica, e o aparato psicofísico do homem se ajusta completamente às exigências do mundo exterior, das ferramentas, das máquinas - em suma, uma função individual. $\mathrm{O}$ indivíduo é destituído de seu ritmo natural, determinado pela estrutura de seu organismo; seu aparato psicossocial é adaptado a um novo ritmo através de uma especialização metódica de músculos, que funcionam separadamente, e estabelece-se uma economia ótima de forças correspondente às condições de trabalho (Weber, 1974, pp. 301-302).

No trecho acima, Weber revela que a disciplina fabril, além de ser fator racionalmente orientado, erige-se como um mecanismo desumanizante, na medida que este novo sistema de organização e conduta no trabalho é orientado exclusivamente por princípios econômicos, representando os mesmo pressupostos que sustentam a máxima impessoal também identificada por este autor como aspecto fundamental da instituição burocrática moderna (Bendix, 1986; Weber, 1974). Mais uma vez, percebese nesta orientação racional um desenvolvimento teleológico da função administrativa que, por conseguinte, se constitui historicamente para atender à dupla finalidade de estruturar o sistema de trabalho da maneira mais eficiente possível e também de obter o máximo de rendimento do trabalhador (Gorz, 1980). Neste sentido, nenhuma outra personagem foi tão bem sucedida em descrever a operacionalização da disciplina fabril quanto o engenheiro americano Frederick Wislow Taylor. Ainda de acordo com a citação anterior, verificamos que o mérito das ideias deste americano, enquanto doutrina sistemática da racionalidade disciplinar da fábrica moderna, foi reconhecido pelo próprio Weber.

Apesar da aproximação destes autores ser controversa nas ciências sociais, a perspectiva de Weber sobre a orientação racionalizante da sociedade pode ser considerada como complementar à perspectiva 
histórica de Marx, ambas sendo úteis na compreensão dos princípios que irão fundamentar a gestão moderna. Neste sentido, o que é importante notar no pensamento weberiano sobre o capitalismo moderno é a ideia de que seu 'espírito' reside em nova ética do trabalho, centrada na formação de uma propensão psicológica contrária àquela presente nas sociedades pré-modernas, especialmente aquelas centradas na vida religiosa contemplativa: o trabalho representa uma pena, um suplício na terra que será compensado com o gozo no paraíso. Assim, sob o ponto de vista psicológico, é na vocação para o trabalho que se sustentou ideologicamente o empreendedor industrial e, em seguida, o administrador profissional assalariado. Conjuntamente às ideias de fragmentação interna do processo de trabalho, da perda de autonomia do trabalhador e da disciplina sistemática e metódica, a vocação para o trabalho constitui o que podemos entender como o ethos da gerência na empresa capitalista.

Em síntese, sob o ponto de vista da organização do trabalho, o que se evidencia pela industrialização é que este processo histórico provocou transformações tecnológicas e da força de trabalho que impetraram nova ordem social na civilização ocidental. Dentro do nosso interesse de investigação, importa destacar que, dentro do sistema fabril e a partir destas novas referências práticas, esboçam-se os princípios do Management.

\section{O MOVIMENTO DOUTRINÁRIO do MANAGEMENT}

Dizer que o Management foi uma instituição constituída historicamente pelo desenvolvimento do capitalismo industrial no Ocidente não revela muito sobre o momento exato de emergência desta instituição. Apesar de ser correto considerar que o aparecimento dos princípios fundamentais do pensamento administrativo moderno ocorreu gradativamente e ao longo do desenvolvimento do modo capitalista de produção industrial, existe um entendimento por parte dos historiadores especializados no Management de que o marco histórico de nascimento desta instituição é o momento em que a gestão do processo industrial se torna sistemática (Jenks, 1960).

O movimento doutrinário de administração sistemática é marcado por diferentes etapas; o desenvolvimento destas ocorre de maneira desarticulada, por iniciativa de diferentes grupos profissionais ligados a diferentes ramos industriais de diferentes regiões, que se organizaram em momentos distintos. Contudo, para melhor demonstrar os principais aspectos de transição do saber gerencial empírico da administração sistemática, Jenks (1960) enumera três etapas fundamentais.

Em um primeiro momento, os problemas de organização e gestão do trabalho industrial eram resolvidos de forma ad hoc, pelos próprios gestores envolvidos diretamente neste processo. Um segundo momento diz respeito a fase em que os procedimentos para a solução dos problemas de gestão na empresa industrial eram deliberadamente planejados por meio de experimentação e pesquisa sistemática, mas ainda desenvolvidos exclusivamente dentro da firma em que estes ocorriam. Finalmente, o terceiro momento corresponde a sistematização da prática de gestão, ou seja, quando os procedimentos de organização e gestão eram feitos tendo por referência aquilo que outras firmas do mesmo ramo estavam fazendo. É neste terceiro momento que o saber de gestão passa do interior das firmas para uma esfera exterior, criando uma dimensão institucional.

Apesar do pioneirismo da Inglaterra na Revolução Industrial, foi nos Estados Unidos que a sistematização das práticas racionalizadoras da gestão do trabalho na indústria se desenvolve primeiramente (Hobsbawm, 2000). A preocupação com a sistematização da gestão nos Estados Unidos emerge a partir da necessidade daquele país pela qualificação da mão-de-obra após a drástica expansão industrial nos anos subsequentes à Guerra da Secessão (Jacques, 1996), e se institucionaliza por meio de um movimento específico dentro das associações profissionais de engenharia, denominado por movimento do works management. Nos principais países europeus industrializados, a administração sistemática se institucionaliza somente após 1900, de forma similar e acompanhando o movimento norte-americano (Jenks, 1960). 


\section{A ENGENHARIA E A CONSTITUIÇÃo do MOVIMENTO WORKS MANAGEMENT}

De acordo com Pollard (1965), a função de gerência que caracteriza o Management surge no momento em que o controle dos trabalhadores envolvidos nas atividades produtivas exige maior número de pessoas, tendo em conta que a especialização da gestão na atividade industrial se dava pela amplitude do comando, mas também devido à maior complexidade das atividades produtivas que emerge com a mecanização da manufatura, processo tecnológico que, além de possibilitar maior racionalização das tarefas, teve por consequência um enorme aumento no volume produzido, em comparação com o modelo de produção artesanal.

É por isso que, a partir do advento do sistema fabril, a função do administrador vai deixando de configurar-se exclusivamente pela figura do capataz, para gradualmente delinear-se como atividade mais sofisticada, que exige conhecimento especializado. Apesar disto, Pollard (1965) salienta, em sua investigação da gestão nas fábricas inglesas da Revolução Industrial, que esta atividade se desenvolve de forma empírica, mais especificamente, à medida que os problemas práticos do controle e da operacionalização do sistema fabril vão exigindo novas concepções da função gerencial. Tendo em conta que os problemas ad hoc de gestão e organização se confundiam com as exigências técnicas específicas do tipo de manufatura a que a indústria se dedicava, era natural que o profissional que se responsabilizasse por esta nova atribuição (a organização e coordenação do processo de trabalho) fosse o mesmo que era responsável pelo desenvolvimento do novo aparato tecnológico da empresa. E esse profissional era o engenheiro.

Apesar de um esforço embrionário já na Revolução Industrial inglesa pela sistematização de princípios gerais da organização e da gestão das unidades fabris (Pollard, 1965), é somente na segunda metade do século dezenove e em outra região que a questão da organização do trabalho se apresenta como assunto de maior interesse para os técnicos da indústria. Assim, nos Estados Unidos, a classe de engenheiros começa a se organizar logo após o fim da Guerra Secessão para tratar de problemas práticos específicos, referentes à organização do trabalho industrial naquele país, tendo em conta que este passava por drástico crescimento industrial e tecnológico que não estava sendo acompanhado no mesmo ritmo pela questão da qualificação da mão de obra (Jacques, 1996; Jenks, 1960).

No momento em que a intensificação tecnológica eleva a importância do engenheiro dentro do processo fabril, esta classe profissional se destaca enquanto um núcleo para a interação e sistematização disciplinar. Assim, além de servir de arena para a discussão dos problemas tecnológicos específicos da indústria (problemas quanto ao maquinário, ao tipo de materiais etc.), as associações de engenharia foram os primeiros locais de conscientização coletiva dos problemas de gestão de recursos e processos, especialmente aqueles que ocorriam dentro da oficina fabril. Questões como o custeio de matéria-prima, o salário dos operários, o controle de estoques, eram alguns dos principais problemas enquadrados nesta matéria (Jenks, 1960).

Nos Estados Unidos de final do século dezenove, as associações de engenheiros foram patrocinadas por empreendedores de jornais especializados, que viam nesta medida uma importante oportunidade de negócio, tendo em vista os ganhos com uma publicidade direcionada. Por outro lado, estes jornais especializados também representaram importantes fóruns de discussão dos problemas de gestão das oficinas, como sugere o comentário de Jenks (1960, p. 431) sobre alguns destes veículos:

O primeiro entre outros a se tornar um veículo para a discussão foi o American Machinist (Nova York), um jornal semanal com um correspondente internacional, que, sob o comando de John A. Hill se tornou um dos mais destacados jornais comerciais no país. Um de seus editores, F. A. Halsey, inventou um amplo plano de incentivo. O jornal era um fórum ativo de calorosa controvérsia sobre sistemas de salários e matérias relacionadas, mas também se dava considerável atenção a outras mudanças nas oficinas mecânicas. O principal jornal britânico semanal Engineering, publicou longas séries de artigos sobre salários e sistemas de custo de forma tão competente quanto os simpósios sobre os métodos americanos de trabalho em oficinas. 
O autor lista ainda uma série de outros jornais ingleses e norte-americanos da área de engenharia que participaram ativamente da disseminação das novas idéias do movimento works management. Nos Estados Unidos, um dos mais importantes fóruns foi o periódico da Associação Americana dos Engenheiros Mecânicos (ASME, em inglês), o Transations, principal veículo de divulgação e debate utilizado pelos principais líderes do movimento, dentre eles Henry Gantt, Frank Gilbreth, Harrington Emerson e Frederick Wislow Taylor. Foi neste periódico que, na década de 1890, Taylor se inseriu vigorosamente na causa do movimento, e apresentou sua concepção sobre as principais questões dos problemas da gestão de oficinas, como por exemplo, a questão dos salários (Wrege \& Greenwood, 1991). Foi a partir destas discussões em particular que começou a surgir a ideia de que o saber da organização da empresa fabril deveria corresponder a um campo exclusivo de formação, denominado por engenharia industrial.

Para se diferenciar do movimento original do works management, Taylor utilizou, a partir da década de 1900, a denominação Scientific Management. Esta nova doutrina foi elaborada por Taylor com a colaboração de um grupo restrito e respeitado de engenheiros e outros profissionais, e nada mais era do que uma poderosa síntese dos principais pontos debatidos no movimento do works management, pontos estes que já haviam sido assimilados por uma audiência interessada.

O sucesso da doutrina de Taylor foi tão grande que é a ele que se costuma atribuir grande parte dos princípios que, na verdade, haviam sido desenvolvidos dentro do movimento anterior, no qual ele participou (Jenks, 1960). Por outro lado, é preciso admitir que o taylorismo foi o movimento doutrinário responsável pela rápida adoção da administração sistemática nos Estados Unidos e em outras partes do mundo, e que foi dentro deste movimento que surgem duas importantes forças para a consolidação do Management: o setor de consultoria em gestão (Kipping, 1997) e figura do engenheiro industrial com formação exclusiva em gestão e organização (Jenks, 1960), fato marcante para a consolidação do Management.

\section{O PAPEL DO TAYLORISMONA INSTITUCIONALIZAÇÃO dO MANAGEMENT}

Na verdade, a notoriedade do taylorismo se deve antes ao fato de que este movimento doutrinário tem tido maior impacto na sociedade americana do que aquele que lhe precedeu (Jacques, 1996; Jenks, 1960; Wrege \& Greenwood, 1991). Assim, já no período entre as guerras mundiais, praticamente em todos os tipos de organizações - econômicas e não econômicas - se observa a aplicação dos princípios sintetizados por Taylor. Neste período, o taylorismo também se expande fora dos Estados Unidos, especialmente nos países industrializados da Europa (Kipping, 1997), no Japão (Sasaki, 1992) e mesmo na Rússia comunista (Braverman, 1974). Os veículos utilizados e as formas adotadas para a expansão deste movimento nos quatro cantos do mundo foram diversos; mas, de modo geral, envolveram organizações civis ou governamentais criadas exclusivamente para este fim ou para outros nos quais a adoção da doutrina de Taylor representava significativa contribuição.

Nos Estados Unidos, a entidade mais bem sucedida na disseminação do taylorismo foi a Taylor Society, organização fundada em 1912 por dois graduados em uma escola de negócios juntamente com outros engenheiros próximos a Taylor. Bruce e Nyland (2001) informam que esta sociedade teve grande impacto na promoção do taylorismo até meados do século vinte; uma das suas maiores contribuições foi a de ter sido o centro para a constituição de importante rede de engenheiros, homens de negócio e cientistas sociais interessados no Management. Esta rede se formou especialmente a partir do debate estabelecido no boletim da Taylor Society. Além de servir como um veículo para a disseminação das ideias de Taylor e seus proponentes, uma importante característica do boletim da Taylor Society era estimular a discussão sobre os casos concretos de aplicação dos princípios do Scientific Management, bem como os avanços obtidos com os desdobramentos deste sistema.

Na Europa, o taylorismo também foi alavancado por associações equivalentes a Taylor Society, tais como a Commission Générale de l'Organisation Scientifique du Travail e o Comité National de 
l'Organisation Française na França; a Verein beratender Organisatoren e o Reichskuratorium für Wirtschaftlichkeit (Corpo de Eficiência Nacional) na Alemanha, o Management Research Groups e o National Institute of Industrial Psycology na Inglaterra e o International Management Institute de Genebra. Este último teve importância fundamental na articulação internacional dos diversos esforços de disseminação do taylorismo e de outras correntes do Management, tendo sua influência chegado até mesmo ao Brasil, através do Idort (Amaral, 1961). A promoção deste movimento na Europa também foi apoiada pela via política, especialmente na França, na Rússia e na Alemanha. Neste último país, o taylorismo se insere sob o nome de movimento de racionalização, e é incorporado à política de Estado a partir da ascensão do partido nazista na década de 1920 (Kipping, 1997). Também atuaram diretamente na promoção do taylorismo na Europa os grupos empresariais, como foi o caso do suporte dado à Commission Générale de l'Organisation Scientifique du Travail pelo governo francês e por um grupo de importantes industriais daquele país, entre eles Louis Renault e André Citroën (Kipping, 1997). O suporte financeiro e político dos industriais também foi dado na criação do National Institute of Industrial Psycology, órgão governamental de promoção das práticas e princípios tayloristas na Inglaterra.

No Japão, o taylorismo teve grande ímpeto a partir do emergente setor elétrico, onde engenheirosempreendedores resolvem adotar as técnicas gerenciais que estavam sendo praticadas nas empresas congêneres no ocidente. Um importante exemplo foi a Companhia Mitsubishi que, logo após sua fundação no início da década de 1920, realiza uma cooperação técnica com a Empresa Americana Westinghouse, no sentido de se ajustar à produção em massa de componentes elétricos. Deste consórcio, a japonesa Mitsubishi incorporou os métodos de estudo de tempos e movimentos e o sistema de pagamentos da correspondente norte-americana, iniciando um ciclo vigoroso de esforços em direção ao estilo americano de gerenciamento (Sasaki, 1992).

Além destas iniciativas, outra de grande impacto para a promoção do taylorismo foi emergência de firmas de consultoria fundada na Administração Científica. Neste sentido, Kipping (1997) considera que o setor de consultoria em gestão praticamente se inaugura com estes esforços. Tendo-se estabelecido nos Estados Unidos e nos principais países europeus, estas firmas eram conduzidas em sua maioria por engenheiros ou ex-professores das escolas de negócios norte-americanas. Dois célebres consultores que estabeleceram escritórios tanto nos Estados Unidos quanto na Europa foram o coronel Lyndall Urwick e o francês radicado nos Estados Unidos Charles Bedaux. Este último teve grande influência neste país e na Grã-Bretanha, durante as décadas de 1920 e 1930. Até os proponentes diretos da Administração Científica, como o casal Gilbreth e o engenheiro Harrington Emerson realizaram diversos trabalhos de consultoria fora dos Estados Unidos (Kipping, 1997). De certa maneira, o rápido crescimento da atividade de consultoria em gestão no período entre Guerras nos Estados Unidos e na Europa se deve à preocupação dos industriais em implementar mecanismos mais capazes de minimizar os efeitos da depressão. Neste sentido, a racionalização dos custos promovida pela Administração Científica era um interessante modelo (Bruce \& Nyland, 2001; Kipping, 1997).

Os princípios do Scientific Management também foram importantes para alavancar o ensino sistemático e o desenvolvimento disciplinar da administração de empresas. Isto porque, além de engajar-se diretamente na criação de um campo disciplinar exclusivo para o design do processo de trabalho (denominado 'engenharia industrial', em oposição as outras engenharias (Wrege \& Greenwood, 1991)), Taylor sistematizou uma doutrina que, em sua essência filosófica, legitimava a formação especializada e tecnicamente fundamentada para a prática gerencial. Isso aproximou-o deste movimento doutrinário acadêmicos de cursos de business - que já existiam antes da sistematização das doutrinas de Management, provendo a formação em atividades operacionais de controle, tais como finanças e contabilidade.

Os acadêmicos das escolas de negócios vislumbraram na proposição taylorista de uma 'ciência da administração' a possibilidade de ampliar o status da formação em negócios, elevando-a de uma esfera operacional para o âmbito decisório. Devido a sua morte em meados da década de 1910, Taylor não teve tempo de atuar ele mesmo na integração de sua doutrina nos cursos de business; entretanto isso foi empreendido pelos integrantes da Taylor Society nos anos seguintes à morte do seu mentor - a 
própria fundação deste instituto foi feita por acadêmicos de uma escola de negócios (Bruce \& Nyland, 2001).

Apesar da conformidade do taylorismo com os valores da sociedade norte-americana de início do século vinte - e, talvez, por isso mesmo - a adoção dos princípios de Taylor nas fábricas norteamericanas gerou imediatamente grande revolta por parte dos trabalhadores, que viam nesta doutrina apenas um mecanismo de fazer-lhes trabalhar mais. Bendix (1974) indica que as raízes deste embate entre os trabalhadores e as propostas de Taylor se encontram na disputa entre os sindicatos e a classe industrial, disputa esta denominada por campanha open shop. Como o taylorismo defendia a exclusividade do manager em relação ao controle do processo de trabalho, este sistema doutrinário atendia à intenção do movimento patronal em minar o poder dos sindicatos. Além disso, o Scientific Management tinha uma prerrogativa importante para minimizar a impressão negativa gerada pela truculência do lado patronal na disputa entre capital e trabalho: foi uma doutrina constituída sob o pretexto da cooperação entre patrões e empregados, tendo em conta que Taylor pretendia que seu sistema atendesse aos interesses dos dois lados, pela maximização do ganho econômico (Braverman, 1974).

Por esta aproximação entre as proposições de Taylor e a ideologia dos empreendedores norteamericanos, o taylorismo consegue rapidamente se popularizar no mundo empresarial, mas também devido ao rápido resultado econômico que o capitalista industrial obtinha, ao aplicar estes métodos. Mesmo a denominação científica nesta doutrina revela muito pouco da verdadeira natureza deste sistema, tendo em conta que, além do fato de Taylor não ser um homem de ciência (na concepção acadêmica), as técnicas empreendidas nos estudos de Taylor eram pueris e correspondiam aos procedimentos aplicados na experimentação empírica comum no mundo do trabalho (Wrege \& Greenwood, 1991). Mesmo assim, as técnicas propostas por Taylor conseguem aproximar-se de outras áreas de conteúdo mais acadêmico, como, por exemplo, a psicologia industrial, gerando maior respaldo para este sistema doutrinário e inaugurando uma tradição acadêmica centrada no pragmatismo, na qual se constituíram o pensamento administrativo moderno e os cursos de administração durante o século vinte (Jacques, 1996).

Enquanto propagador do ethos do trabalho comum ao capitalismo industrial, uma importante contribuição do taylorismo foi o reforço da necessidade de separação entre os planejadores e executores do trabalho. Sobre este ponto, Braverman (1981) lembra que a gerência que emerge do sistema fabril caracterizava-se essencialmente pelo controle do sistema decisório do processo produtivo que, no modelo produtivo anterior, a fábrica (manufatura artesanal) era atribuição do executor do trabalho. Neste sentido, o autor dá crédito ao taylorismo por reconhecer que este movimento permitiu a rápida difusão deste princípio, tendo em conta a preocupação de Taylor em promover dentro das fábricas uma nova função para a gerência, baseada no estudo e planejamento do trabalho, mas que tinha por resultado mais significativo o controle do processo de trabalho pela administração.

Em última instância, o princípio da separação entre pensar e executar o trabalho reflete a divisão social e econômica impetrada na era moderna pelo capitalismo, a separação entre possuidores dos meios de produção - onde as técnicas e métodos de administração moderna são importante recurso produtivo - e os possuidores da força física de trabalho. É por este motivo que as preocupações práticas de Taylor e seus seguidores giravam em torno da descoberta da ciência por traz de cada tarefa (ciência sobre como carregar lingotes de ferro, ciência sobre a fadiga dos serviços pesados, ciência sobre como assentar tijolos, etc.). Neste ponto, Braverman (1981, p. 106) considera que

Taylor, no caso, argumenta que o estudo sistemático do trabalho e os resultados deste estudo pertencem à gerência pelas mesmíssimas razões que máquinas, imóveis, instalações etc. pertencem a eles; isto é, custa tempo de trabalho empreender tal estudo, e apenas possuidores de capital podem arcar com tempo de trabalho. Os possuidores de tempo de trabalho não podem eles mesmos fazer o que quer que seja com ele, mas vendê-lo como meio de subsistência. É verdade que esta é a regra nas relações capitalistas de produção e o emprego do argumento por Taylor no caso mostra com 
grande clareza aonde o poder do capital leva: não apenas o capital é propriedade do capitalista, mas o próprio trabalho tornou-se parte do capital.

A partir da colocação acima, podemos notar que o taylorismo somente se propaga porque justifica as relações que se estabeleceram com o capitalismo industrial, onde o gerente moderno é importante artífice. É necessário lembrar que o gerente também é um trabalhador, mas isso não significa dizer que ele se encontra no mesmo patamar que os operários fabris, como se pode perceber pela trajetória histórica desta profissão genuinamente moderna. Com o advento do ensino formal do Management, a competência gerencial se torna ainda mais especializada, e o distanciamento entre estes dois tipos de trabalhadores (gerentes e operários) se amplia. Isto devido ao fato de que, como consequência da sofisticação do tecnicismo na função administrativa - em grande parte, dado pelo desenvolvimento burocrático do ofício gerencial, o administrador moderno eleva-se a uma posição privilegiada de poder dentro do contexto da organização moderna.

\section{As Condições de PropagaÇão do Management a partir da TeOria da Grande EMPRESA}

O contexto que favoreceu a ascensão do administrador profissional também pode ser explicado pela teoria histórica da grande empresa, de Chandler (1977). De acordo com este autor, a grande empresa norte-americana e os grandes trustes que marcaram aquele país, na virada do século dezenove, emergem de um conjunto de cinco grandes acontecimentos históricos diretamente conectados: i) a expansão demográfica para o oeste; ii) a construção da rede ferroviária nacional; iii) o desenvolvimento de um mercado nacional, especialmente nos centros urbanos; iv) o advento de novas tecnologias de produção, onde se destacaram aquelas associadas às novas fontes de energia, como eletricidade e petróleo; e v) a introdução da atividade de pesquisa e desenvolvimento dentro do setor produtivo.

Além de permitir o aumento da demanda interna por produtos da indústria de bens de consumo, a expansão ferroviária induziu o desenvolvimento da indústria de bens de produção, tendo em conta a demanda específica deste setor por ferro e maquinário. Por conseguinte, o crescimento da capacidade produtiva do setor metal-mecânico permitiu que outras indústrias fossem atendidas. Além disso, Chandler considera que a indústria ferroviária foi o primeiro setor a desenvolver o modelo de gestão empresarial burocrática, na medida em que as estradas de ferro se tornam as primeiras grandes corporações. Acompanhando este movimento do setor ferroviário, as indústrias de bens de consumo também desenvolveram complexos sistemas gerenciais a partir de seu rápido crescimento. A partir da criação de uma rede de distribuição e vendas de escopo nacional, várias empresas se viram obrigadas a desenvolver uma estrutura organizacional departamentalizada, centralizada e integrada verticalmente.

Neste sentido, além da integração vertical, o desenvolvimento industrial no início do século vinte nos Estados Unidos foi marcado pela intensa diversificação de produtos. Além de representarem uma adaptação a novos mercados (por exemplo, a mudança da produção do trilho de trem para a produção da estrutura de construção), a diversificação ocorreu em resposta à ampliação da capacidade de distribuição dos departamentos comerciais das empresas. É assim que produtores de um único produto investiram no desenvolvimento da Linha completa (Chandler, 1977). Mas isso foi possível graças à implantação das atividades de Pesquisa e Desenvolvimento [P\&D] dentro da empresa capitalista. Estas divisões representavam um novo fator a exigir maior coordenação entre as divisões produtivas. Diante do estabelecimento deste sistema organizacional complexo é que emerge, durante o desenvolvimento industrial dos Estados Unidos, o administrador profissional assalariado, responsável pela coordenação das divisões e da direção geral da corporação. Exercendo o cargo de maneira profissional - no sentido weberiano do termo - tais administradores de primeira e segunda linha hierárquica tiveram um impacto tão decisivo na sociedade norte-americana do século passado que Chandler (1977) considera que se inaugurou nova categoria de capitalismo, o gerencial. 
Para dar conta destas novas exigências, as corporações desenvolveram organizações específicas para estes fins, com administradores tecnicamente preparados para lidar com mecanismos reguladores mais rigorosos, baseados especialmente no controle estatístico e contábil, e mesmo com as novas técnicas e princípios gerenciais que estavam sendo promovidos pelos movimentos doutrinários anteriormente mencionados; não por coincidência, estes emergiram no mesmo período e local. Estas novas divisões gerenciais especializadas, apesar de maiores e alocando grande número de pessoas e quantidade de recursos financeiros, eram significativamente mais eficientes que o sistema de distribuição rudimentar da economia americana, baseado no representante comercial, tendo em vista sua maior eficiência para dar conta da alta amplitude de escala.

Neste novo modelo integrado de gestão da distribuição e comercialização - que também se estabelece na função de compra de insumos (Chandler, 1977) - o gerente se especializa e amplia significativamente seu poder de controle sobre toda a cadeia produtiva. É importante destacar que esse controle é eminentemente de natureza burocrática, já que é centrado na capacidade técnica e na formalização previamente estabelecidas para o cumprimento de uma função estritamente delimitada e racionalmente orientada, que promove um sistema mecanicamente integrado: cada parte desenvolve suas atividades específicas de maneira precisa e sistematizada, garantindo o funcionamento global da máquina empresarial.

\section{CONSIDERAÇÕES FINAIS}

A reconstrução histórica do Management aqui apresentada nos permite avaliar quais seriam os pressupostos centrais desta instituição, a partir de sua gênese, algo que nem sempre é devidamente observado pelos estudos revisionistas que não adotam a perspectiva histórica em sua análise. No presente trabalho, identificamos na constituição histórica do Management a presença constante de dois aspectos em particular: o pragmatismo - ensejado desde os primórdios da sistematização de práticas modernas de Administração, quando a crescente sofisticação do sistema capitalista condicionou que o capitalista e seus representantes buscassem, na experiência prática, novas formas mais racionais e economicamente mais rentáveis: era o controle sistemático do trabalho e de seu processo de organização, dado de tal forma que eliminasse do trabalhador sua autonomia de decisão sobre o trabalho.

Conforme observamos acima, a teoria da grande empresa de Chandler (1977) se sustenta nos eventos históricos que caracterizaram o peculiar avanço da industrialização nos Estados Unidos. Realmente, o avanço do processo de industrialização está diretamente relacionado à formação institucional do Management pelo fato de que esta instituição se tem constituído historicamente a partir das exigências práticas da atividade industrial, seja com o advento da nova organização do processo produtivo em si (modo fabril), seja a partir das novas exigências da sociedade centrada neste novo sistema econômico. Em relação a este último ponto, é importante ressaltar que, dentro de seus requisitos pragmáticos, o pensamento administrativo também se afirma como elemento ideológico para a sustentação de nova lógica de autoridade, justificada, em primeiro momento, por uma necessidade prática de controle que emerge com o sistema fabril; em um segundo momento, em conformidade ao conteúdo tecnicista do sistema burocrático (Bendix, 1974).

Neste último ponto, a expansão do sistema burocrático, dentro do setor industrial, ocorre primeiramente nos Estados Unidos na virada do século dezenove para o vinte, porque foi naquele local e período que as relações entre os agentes econômicos se organizaram de maneira peculiar, formando um complexo sistema produtivo integrado. Internamente, as corporações tiveram que responder com novas estruturas gerenciais, dando conta de um enorme número de variáveis e processos articulados e interdependentes. Assim, a constituição institucional do Management ocorre naquele país, porque foi o lugar e o momento onde a complexidade sistêmica da industrialização se torna mais aguda, ou seja, na fase em que o capitalismo industrial promove o nascimento de empresas industriais gigantescas, que 
surgem especialmente através da formação dos trustes setoriais formados pelo crescimento e concentração de certas indústrias norte-americanas (Bendix, 1974; Chandler, 1977).

Outra importante consideração sobre o advento histórico do Management é a ideia de que esta instituição emerge da gradual separação entre a propriedade e o controle da empresa capitalista. Um importante marco histórico desta separação foi a emergência e proliferação das empresas de propriedade anônima, possível apenas como desenvolvimento do capitalismo financeiro, no final do século dezenove. A gradual sofisticação do Management enquanto sistema de controle e maximização do ganho capitalista coincide com a aguda complexidade operacional alcançada nas organizações produtivas (que, como observado, teve importante ímpeto a partir do extensivo processo de integração vertical na indústria norte-americana). Este conjunto de fatores e acontecimentos permitiram a rápida ascensão do administrador profissional assalariado, como classe de elevado status naquela sociedade. É assim que, legitimado pelo interesse capitalista, o administrador profissional moderno se fortalece como grupo social por assumir gradativamente o controle geral da empresa, antes exercido pelo empreendedor.

Para finalizarmos nossa reflexão sobre as fontes historiográficas que retratam a emergência do Management, apresentamos alguns pontos que podem ser interessantes para dimensionar o desenvolvimento desta instituição nos tempos atuais. Estes aspectos revelam a perspectiva política na qual o Management se constitui e continua a se reproduzir, e podem indicar pontos de referência para estudos futuros sobre este tema, em especial para o seu entendimento em países como o Brasil, onde o Management se desenvolveu em um contexto diverso que, mesmo tendo sido influenciado pelas principais potências do capitalismo gerencial, não foi de todo condicionado por tais referências culturais e políticas externas.

O Management e a engenharia. A análise da sua trajetória histórica demonstra que, desde seus primórdios, o Management é uma prática exercida especialmente por engenheiros. Isto é significativo, se notarmos quanto a presença destes profissionais ainda é marcante nos postos de gerência profissional de empresas de distintos tamanhos e áreas de atuação. Isto talvez explique a dificuldade que ainda persiste neste campo de saber e prática em se desvencilhar do pragmatismo e da orientação racional-instrumental que permeiam o discurso do Management, especialmente aquele constituído nos Estados Unidos, tendo em conta ter sido este o lugar onde eclodiu o processo de institucionalização destas práticas e saberes (Jacques, 1996). Mesmo em outros lugares, como no caso do Brasil, a introdução do Management foi marcada pelo suporte desta classe dos engenheiros (Amaral, 1961), e, por isso mesmo, foi influenciada pela ideologia tecnicista que lhe permitiu a ascensão política e social dos engenheiros nas sociedades do capitalismo periférico no século vinte (Cardoso, 1972; Dias, 1994).

O papel das consultorias de gestão e das associações de classe na propagação das ideias e princípios do Management. Como observamos em nossa reflexão, as consultorias e institutos de Management tiveram papel central na articulação dos princípios e das ideias que retratam este campo, bem como na consolidação do manager enquanto classe profissional independente e de grande proeminência social em nosso tempo. A investigação sobre estes institutos e consultorias pioneiros pode ser um importante ponto de referência para desvendar a natureza desta instituição em diferentes países, tendo em conta que o esforço de introdução e de estabelecimento dos movimentos doutrinários de Management em um país deve ter em conta o contexto social e político deste, vigentes à época de tais tentativas. Este certamente é o caso do Brasil, que teve sua primeira tentativa de introdução do movimento doutrinário de Management na fundação do Idort na década de 1930, um instituto que, por sua proposta de fundação, deve ser considerado como esforço idêntico àqueles que se estabeleceram na mesma época em países europeus industrializados (Vizeu, 2008). Curiosamente, o Idort - uma organização existente até os dias atuais - teve sua origem marcada por dificuldades e reviravoltas que a fizeram alterar drasticamente sua proposta inicial de instituto de disseminação do Management no Brasil (sobre a história deste instituto em seus primeiros anos, ver Amaral (1961)). Isto é um importante indício de que as peculiaridades de cada contexto nacional marcam e condicionam o esforço político de introdução e disseminação deste instituto, sendo tais esforços importantes objetos para a investigação historiográfica que seja capaz de informar peculiaridades do Management em cada país. 
O papel das escolas de administração. Em relação ao desenvolvimento e à propagação do pensamento administrativo moderno, vimos que as escolas de negócios, mesmo sendo anteriores a própria consolidação do Management enquanto disciplina, foram beneficiadas pelos pressupostos filosóficos das doutrinas deste novo campo disciplinar. Por outro lado, com a introdução do Management em seus programas curriculares, as escolas de negócios passam a priorizar em sua formação a prática de gestão e tomada de decisão, impelidas especialmente com a crescente demanda pela profissionalização do Manager. Resta-nos indagar se o único papel destas escolas foi o de legitimar o Management, tendo em conta a importância que estas tiveram no desenvolvimento do pensamento administrativo ao longo do século vinte. Por isso, o estudo das escolas de Administração deve considerar tanto seu papel como legitimadores dos princípios do Management entre as grandes corporações, quanto à sua renovação dentro deste meio. Este duplo papel explica por que algumas escolas se envolvem sistematicamente na consultoria, como, por exemplo, a escola de negócios de Harvard, uma prática que facilita a disseminação de novos modelos gerenciais no mundo corporativo. No Brasil, tem sido observado o papel central das escolas de administração como disseminadoras do Management a partir da década de 1960, especialmente diante de um processo de importação de conhecimento advindo dos Estados Unidos. Este é o caso das escolas da Fundação Getulio Vargas (Fischer, 1984). De resto, estudos que permitam melhor dimensionar a participação destas escolas na disseminação e 'renovação' do Management podem ser formas interessantes de reconhecer o papel ideológico destas escolas na consolidação dos princípios basilares desta instituição.

O entendimento do Management fora dos Estados Unidos e do Reino Unido. Por fim, apontamos como uma importante implicação sobre a discussão histórica da gênese do Management o reconhecimento da hibridização desta instituição em contextos nacionais cuja trajetória histórica é significativamente diferente dos dois principais países anglo-saxões. Sendo preocupação corrente de autores latino-americanos, a hibridização de referências institucionais em processos pós-colonialistas de influência pode ser uma interessante maneira de se avaliar a introdução do Management no Brasil, que, mesmo tendo sido pretendida nos mesmos moldes que os países europeus industrializados - ou seja, articulada no período entre as guerras mundiais e por meio de um instituto de Management fundado pela classe de engenheiros nos mesmos moldes dos congêneres europeus (Amaral, 1961) somente foi consolidada tardiamente e de forma anacrônica em relação ao país de origem. Além disso, pesquisas sobre o empresariado brasileiro revelam que a adoção de uma gestão profissional no Brasil foi condicionada pelas referências patrimonialistas ainda presentes na sociedade da época (Cardoso, 1972). Este fato é relevante para compreender a própria identidade do Management em nosso país, tendo em conta que, segundo a teoria histórica de Chandler (1977), o Management se institucionaliza em decorrência da separação entre a propriedade e a autoridade gerencial (que, no sistema burocrático moderno, é tecnicamente legitimada), formando aquilo que o autor chamou de capitalismo gerencial. No momento que a grande empresa brasileira divisionada e de capital aberto não incorpora plenamente o princípio burocrático de separação da propriedade e do controle administrativo (Martins, 1973), uma importante prerrogativa do Management não se estabelece em nosso país naquele período - ou seja, a livre direção empreendida por administradores assalariados orientados por princípios e técnicas gerenciais racional-instrumentais (Cardoso, 1972).

Este último indício em particular é sinal de que, para entendermos o Management em nosso país, devemos debruçar-nos primeiro em nossa própria história. Assim, em conformidade com os esforços que defendem a ampliação de estudos históricos na academia brasileira de Administração e organizações (Vizeu, 2010), apontamos algumas possibilidades. Primeiramente, devemos considerar as especificidades com as quais foi feita a recepção e o desenvolvimento das doutrinas de Management em nosso país, na esfera privada em face do engajamento da elite industrial paulista (Vizeu, 2008) e, na esfera pública, com o advento do Estado Novo na era Vargas (Wahrlich, 1983). Neste sentido, acreditamos que estudos historiográficos específicos sobre a prática e a mentalidade gerencial deste período e contexto organizacional podem explicar matizes ainda pouco sinalizados sobre nossa trajetória histórica gerencial, elementos estes que já foram apontados por alguns estudos de décadas passadas (por exemplo, Cardoso, 1972; Martins, 1973), mas que ainda foram pouco explorados. 
Finalmente, esforços em programas de mestrado e doutorado podem ser feitos, aproveitando-se a recente expansão das fontes de dados históricos, fomentada especialmente pela iniciativa dos grandes grupos empresariais em conservar sua memória (no formato dos arquivos históricos próprios), bem como da expansão e digitalização do acervo dos arquivos históricos (como é o caso do CPDOC da Fundação Getulio Vargas), aspectos que facilitam muito a viabilização deste tipo de pesquisa.

\title{
Artigo recebido em 14.01.2010. Aprovado em 05.07.2010.
}

\section{NOTA}

\begin{abstract}
${ }^{1}$ É preciso ressaltar que, no presente trabalho, consideramos o Management apenas a partir da esfera de empresas econômicas. Isto foi devido exclusivamente por uma questão de escopo analítico, que, aqui, se centrou na construção histórica da atividade econômica capitalista. Entretanto, não assumimos que esta instituição não se tenha manifestado no âmbito da gestão pública. Isso é evidenciado especialmente pelo olhar de Weber (1974) sobre a racionalização administrativa do Estado prussiano, de onde este autor se inspirou para delinear sua análise ideal-típica da organização burocrática moderna (Bendix, 1974). Além disso, temos de ter em conta que a racionalização da administração de empresas se integrou de tal forma à racionalização da administração pública que, na trajetória histórica desta última, encontramos a presença dos mecanismos característicos da gestão de negócios, como, por exemplo, no movimento do New Public Management (Dunleavy, P., \& Hood, C. (1994). From old Public Administration to New Public Management. Public Money \& Management, 4(3), 9-16). Sobre este aspecto, gostaríamos de agradecer a contribuição do avaliador Ad hoc da RAC por ter alertado para este problema.
\end{abstract}

\section{REFERÊNCIAS BIBLIOGRÁFICAS}

Amaral, P. F. (1961). Trinta anos de atividades no campo da organização científica. Revista de Organização Científica do IDORT, 30(353), 5-26.

Bedeian, A. G. (2004). The gift of professional maturity. Academy of Management Learning and Education, 3(1), 92-98.

Bendix, R. (1974). Work and authority in industry. Berkeley: University California Press.

Bendix, R. (1986). Max Weber: um perfil intelectual. Brasília: Editora da Universidade de Brasília.

Braverman, H. (1974). Trabalho e capital monopolista. Rio de Janeiro: Zahar.

Braverman, H. (1981). Trabalho e capital monopolista (3a ed.). Rio de Janeiro: Zahar.

Bruce, K., \& Nyland, C. (2001). Scientific management, institutionalism, and business stabilization: 1903-1923. Journal of Economic Issues, 35(4), 955-978.

Cardoso, F. H. (1972). Empresário industrial e desenvolvimento econômico no Brasil (2a ed.). São Paulo: Difusão Européia do Livro.

Chandler, A. D. (1977). The visible hand: the managerial revolution in American business. Cambridge: Harvard University Press.

Dias, J. L. M. (1994). Os engenheiros do Brasil. In A. C. Gomes (Coord.). Engenheiros e economistas: novas elites burocráticas. Rio de Janeiro: FGV.

Dobb, M. (1980). A evolução do capitalismo (7a ed.). Rio de Janeiro: Zahar. 
Fischer, T. (1984). Administração pública como área de conhecimento e ensino: a trajetória brasileira. Revista de Administração de Empresas, 24(4), 278-288.

Gorz, A. (1980). O despotismo de fábrica e suas conseqüências. In A. Gorz (Org.), Crítica da divisão do trabalho (pp. 81-89). São Paulo: Martins Fontes.

Hobsbawm, E. J. (1996). A era do capital. Rio de Janeiro: Paz e Terra.

Hobsbawm, E. J. (2000). Da revolução industrial inglesa ao imperialismo (5a ed.). Rio de Janeiro: Forense Universitária.

Jacques, R. S. (1996). Manufacturing the employee: management knowledge from the $19^{\text {th }}$ to $21^{\text {st }}$ centuries. London: Sage.

Jenks, L. H. (1960). Early phases of the management movement. Administrative Science Quarterly, 5(3), 421-447.

Kipping, M. (1997). Consultancies, institutions and the diffusion of Taylorism in Britain, Germany and France, 1920s to 1950s. Business History, 39(4), 67-83.

Landes, D. S. (1994). Prometeu desacorrentado: transformação tecnológica e desenvolvimento industrial na Europa Ocidental. Rio de Janeiro: Nova Fronteira.

Martins, J. S. (1973). Conde Matarazzo, o empresário e a empresa. São Paulo: Hucitec.

Marx, K. (2002). O capital (Vol. 6, 20a ed.). Rio de Janeiro: Civilização Brasileira.

Pollard, S. (1965). The genesis of modern management: a study of the industrial revolution in Great Britain. Cambridge: Harvard University Press.

Sasaki, S. (1992). The introduction of scientific management by the Mitsubishi Electric Engineering Co. and the formation of an organised Scientific Management movement in Japan in the 1920s and 1930s. Business History, 34(2), 12-27.

Üsdiken, B., \& Kieser, A. (2004). Introduction: history in organization studies. Business History, 46(3), 321-330.

Vizeu, F. (2008). Management no Brasil em perspectiva histórica: o projeto do IDORT nas décadas de 1930 e 1940. Tese de doutorado, Fundação Getulio Vargas, São Paulo, SP, Brasil.

Vizeu, F. (2010). Potencialidades da análise histórica nos estudos organizacionais brasileiros. Revista de Administração de Empresas, 50(1), 37-47.

Wahrlich, B. M. S. (1983). A reforma administrativa da era de Vargas. Rio de Janeiro: Fundação Getulio Vargas.

Weber, M. (1974). Ensaios de sociologia (3a ed.). Rio de Janeiro: Zahar.

Wrege, C. D., \& Greenwood, R. G. (1991). Frederick W. Taylor: the father of scientific management, myth and reality. Romewood, US: Business One Irwin. 